\title{
INVESTIGATION OF STEEL FIBRE PULLOUT AND MODELING OF BRIDGING BEHAVIOUR IN SFRC
}

\author{
Ulvis Skadins $^{1}$, Janis Brauns ${ }^{2}$ \\ Department of Structural Engineering, Latvia University of Agriculture, \\ Academy Str. 19, LV-3001 Jelgava, Latvia \\ E-mails: ${ }^{1} u l v i s . s k a d i n s @ l l u . l v$ (correspondingauthor); ${ }^{2}$ janis.brauns@llu.lv
}

Received 02 December 2011; accepted 20 July 2012

\begin{abstract}
By adding fibres to concrete mix the objective is to bridge discrete cracks providing for some control to the fracture process and increase the fracture energy. Fibres become active mainly when cracking starts and deformation of the fibre occurs. Pullout tests with four types of fibres with different orientation, embedment lengths, and concrete strengths are performed to simulate the bridging process. Fibre pullout behaviour is analysed for relatively small slippage displacement to keep it close to real designing situations. The test results show significant effect of fibre type on pullout behaviour, nevertheless the effect is intangible on fibres inclined at 30 degrees or more. An effective displacement is introduced, derived from experimental force-slip curves, when fibre becomes involved in bridging. Based on the effective displacement and simplified average force-slip curves a numerical model is proposed to analyse the tensile stresses transferred by fibres crossing a crack.
\end{abstract}

Keywords: bond strength, crack width, orientation angle, pullout test, stress transfer.

\section{Introduction}

Randomly distributed or aligned short steel fibres are often used to reinforce cementitious materials, since they offer resistance to crack initiation and, mainly, to crack propagation. In steal fibre reinforced concrete (SFRC) of low fibre volume fraction the principal benefits of the fibres are effective after matrix cracking. Crossing the crack the fibres guarantee a certain level of stress transfer between both faces of the crack and provide to the composite a residual strength, which magnitude depends on the fibre, matrix and fibre-matrix interface properties.

The mechanical performance of fibre reinforced concrete (FRC) is highly influenced by the fibre dispersion, since the effectiveness of fibres depends on the orientation of fibres, their location and arrangement within concrete (matrix). Considering the above-mentioned and that fibre and matrix are bonded together through a weak interface, study of the interfacial be- haviour is important for understanding the mechanical behaviour of such composites.

The effectiveness of a given fibre in the stress transfer can be assessed using a single fibre pullout test where fibre slip is monitored as a function of the applied load on the fibre. The data derived from single pullout tests can give relevant contribution to optimisation of the properties of FRC.

Stress transferring capacity by steel fibres is variable and depends on crack width. Due to several stages the stress strain relationship is rather complicated (Robins et al. 2002). It is close to zero at the moment when crack just occurs, then the capacity grows and reaches its plateau and slightly goes down to zero when crack is as wide as half of fibre length. Real structures must be calculated according to serviceability and ultimate limit states that leads to constructions with relatively small crack widths. Therefore besides complete collapse analysis of FRC element, a special attention must be paid on early stage of cracking. 
A numerical model, based on experimental data, developed in this study takes the concrete strength, type of fibre, orientation angle and crack width into account.

\section{Pullout tests}

Short fibres act as bridging elements over a crack. The behaviour of fibres at the crack can be simulated by single fibre pullout test (Fig. 1). As the fibres in FRC elements have random orientation and they are uniformly distributed through matrix, they have different embedment lengths and inclination angles at the crack. Recent investigations show that these aspects play important role on pullout behaviour and the energy used for pullout process (Laranjeira et al. 2010).
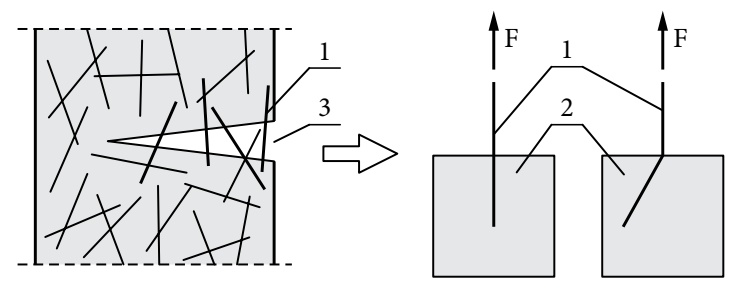

Fig. 1. Pullout test as the simulation of bridging process in cracked SFRC structure, where 1 - fibre, 2 - matrix, 3 - crack

This research is mainly based on various pullout experiments performed in Latvia University of Agriculture during years 2010 and 2011. The tests included specimens with different fibre embedment lengths, concrete strengths, fibre types and orientation angles.

\subsection{Specimen data}

The test specimens were concrete prisms with a single fibre in each one. Dimensions of the prisms were $40 \times 40 \times 60 \mathrm{~mm}$. The fibre embedment length was mainly $25 \mathrm{~mm}$, which is a half of the fibre full length. To analyse the effect of the fibre orientation, they were inclined at four different angles of $0,30,45$, and 60 degrees. In addition, fibres with the embedment length of $15 \mathrm{~mm}$ and inclination angle of 0 degrees were tested. There were 114 specimens altogether.

Because of the small dimensions of specimens, fine-grained concrete was used. The mean concrete strength was 55.1 MPa with variation coefficient of 0.016 . In addition, concrete with strength of $13.0 \mathrm{MPa}$ and 25.0 MPa was used for specimens with straight fibres without inclination.

Four different types of fibres were used: smooth $(\mathrm{S})$, hooked (H), crimped (C) and flat ended (FE).
These types were chosen as the most representative of fibres available at present time in Latvia. Although flat-ended fibres are not common in Latvian market, they are rather innovative and therefore interesting to study. The fibre diameter for all types was $0.75 \mathrm{~mm}$ and length $-50 \mathrm{~mm}$. The yield strength of the fibre steel was $1100 \mathrm{MPa}$.

\subsection{Test setup}

The test setup is shown in Fig. 2. The concrete prisms were fixed in steel/aluminium frame. There was a round plate fixed to the fibre. A wedge grip was used to take hold of the loosed part of the fibre. Three LVTD's (HBM WETA1/2) were attached to the frame to measure the distance between the specimen and the plate. S9 type force transducer (max. load $50 \mathrm{kN}$ ) was used for force measurements. Tests were performed under closed looped conditions by controlling position of the machine head and using test speed of $1 \mathrm{~mm}$ per minute.

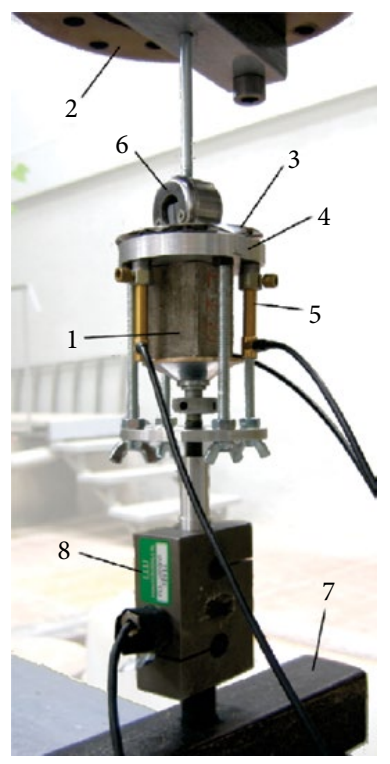

Fig. 2. Pullout test setup: 1 - concrete specimen, 2 - Hydraulic Zwick machine head, 3 - plate, fixed to fibre, 4 - frame, 5 - LVTDs, 6 - wedge grip, 7 - support, 8 - S9 force transducer

\section{Results and discussion}

In general, the pullout behaviour of every tested fibre can be described by a curve consisting of pre-peak and post-peak branch (Fig. 3). The average pullout load-displacement curves for the tested series, with orientation angle of zero degrees, are shown in Fig. 4. The pre-peak parts of pullout-displacement curves consist of a linear and non-linear part. The first one is associated with 


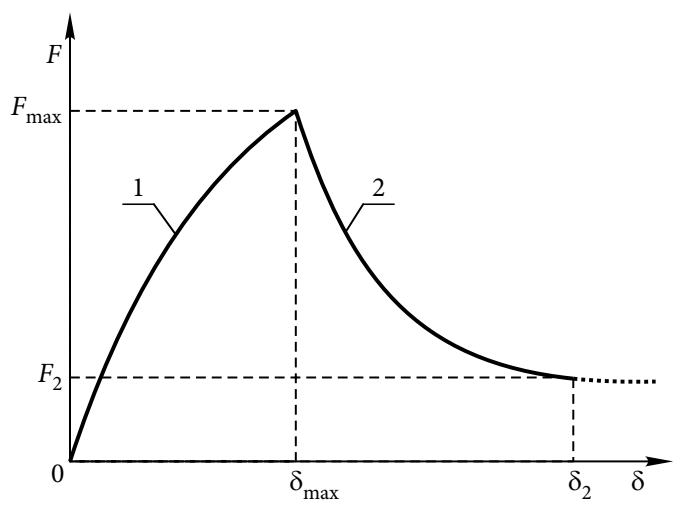

Fig. 3. Principal pullout curve: 1 - ascending branch, 2 - descending branch

the elastic bonding, whereas the nonlinear part starts with the micro cracking of the interface, corresponding to the debonding process and straightening of fibres. For smooth fibres (Fig. 4a) the non-linear part of the ascending branch has a relatively small amplitude, since it starts very close to the peak load. When the peak load is attained, a sudden drop is observed, which corresponds to an abrupt increase of damage at the fibreconcrete interface. Note that fibre-concrete friction is the main mechanism of the pullout behaviour. In this part of the post-peak branch, the load decreases with the increase of displacement, since the available frictional area decreases, as well as the roughness of the failure surface. The post-peak load decay in the case of hooked, headed and crimped fibres was not so abrupt than in the case of smooth fibres. With the increasing displacement the mechanical anchorage of these fibres starts to become progressively mobilised.

\subsection{Analytical modelling of pullout response of fibres}

In order to determine the fibre pullout energy the parameters of the load-displacement relationship that best fitted the experimental pullout load-displacement curves of all series were obtained. On the basis of average experimental curves shown in Fig. 4 the parameters of analytical relationships were obtained by using minimization procedure:

$$
\sum_{i=1}^{N}\left|F_{i}\left(\delta_{i}\right)_{\exp }-F_{i}\left(\delta_{i}\right)_{\text {anal }}\right| \rightarrow \min
$$

where $N$ - the number of points on the experimental and analytical curves; $F_{i}$ - force in fibre; and $\delta_{i}$ - fibre displacement.

The approximation of experimental curves was performed by using the following relationships: for ascending branch $\left(0<\delta \leq \delta_{\max }\right)$ :

$$
F(\delta)=F_{\max }\left[1-\left(\frac{\delta_{\max }-\delta}{\delta_{\max }}\right)^{\alpha}+\beta \frac{\delta}{\delta_{\max }}\left(\frac{\delta_{\max }-\delta}{\delta_{\max }}\right)^{\gamma}\right]
$$

and descending branch $\left(\delta_{\max }<\delta \leq \delta_{2}\right)$ :

$$
F(\delta)=F_{\max }\left[1-\left(1-\frac{F_{2}}{F_{\max }}\right)\left(\frac{\delta-\delta_{\max }}{\delta_{2}-\delta_{\max }}\right)^{\eta}\right] .
$$

For smooth (S) fibres with orientation angle of 0 degrees, the descending part can be described by equation (4).

$$
F(\delta)=F_{2}\left[1+\left(\frac{F_{2}}{F_{\max }}-1\right)\left(\frac{\delta_{2}-\delta}{\delta_{2}-\delta_{\max }}\right)^{\eta}\right]
$$

In expressions (2) to (4) typical experimental characteristics $F_{\max }$ and $\delta_{\max }$, which stand for maximum pullout force and the fibre displacement at the maximum force, were used respectively. To describe the descending branch more precisely, the end point of the curves represented by force $F_{2}$ and displacement $\delta_{2}$ was used. The principal pullout curve and the mentioned characteristics are shown in Fig. 3.

Unknown coefficients $\alpha, \beta, \gamma, \eta$ were determined by using minimization procedure (1). The values of mentioned experimental characteristics and the coefficients are condensed in Table 1.

\subsection{Pullout energy}

To estimate the fractural toughness of FRC the pullout energy of fibres was determined. The integration procedures (5) and (6) for the functions (2) to (4) were used.

For ascending part:

$$
W_{1}=\int_{0}^{\delta_{\max }} F(\delta) d \delta
$$

For descending part

$$
W_{2}=\int_{\delta_{\max }}^{\delta_{2}} F(\delta) d \delta
$$

The total energy $W$ is a sum of the pre-peak and post-peak energies:

$$
W=W_{1}+W_{2} .
$$

Based on these calculations fibre pullout energy for different types and inclination angles was found. Thus the fibre type effect at a certain displacement 
Table 1. The values of the typical experimental characteristics of the pullout curves

\begin{tabular}{|c|c|c|c|c|c|c|c|c|c|c|c|c|c|c|c|c|}
\hline & \multicolumn{16}{|c|}{ Fiber inclination angle } \\
\hline & \multicolumn{4}{|c|}{$0^{\circ}$} & \multicolumn{4}{|c|}{$30^{\circ}$} & \multicolumn{4}{|c|}{$45^{\circ}$} & \multicolumn{4}{|c|}{$60^{\circ}$} \\
\hline \multicolumn{17}{|c|}{ Fiber type } \\
\hline & $S$ & $\mathrm{H}$ & $\mathrm{C}$ & $\mathrm{FE}$ & $S$ & $\mathrm{H}$ & $\mathrm{C}$ & $\mathrm{FE}$ & $S$ & $\mathrm{H}$ & $\mathrm{C}$ & $\mathrm{FE}$ & $S$ & $\mathrm{H}$ & $\mathrm{C}$ & $\mathrm{FE}$ \\
\hline \multicolumn{17}{|c|}{ Coefficients } \\
\hline$\alpha$ & 7 & 15 & 9 & 9.5 & 4 & 5 & 3 & 5 & 10 & 4 & 4.1 & 4 & 10 & 5 & 4.2 & 0.78 \\
\hline$\beta$ & 2.4 & 3 & 2.2 & 3.6 & 0.9 & 2.2 & 3 & 3.5 & 1.5 & 2 & 3.2 & 2.6 & 5 & 4.3 & 3.3 & 0 \\
\hline$\gamma$ & 2.33 & 5.36 & 3.27 & 3.5 & 1.33 & 2 & 3 & 2.7 & 2 & 1.6 & 1.95 & 1.9 & 2.22 & 1.92 & 1.15 & - \\
\hline$\eta$ & 24 & 1.2 & 2 & 0.8 & 1.3 & 1.5 & 1.2 & 1.2 & 2 & 0.8 & 0.9 & 2 & 1 & 0.5 & 0.7 & 0.29 \\
\hline \multicolumn{17}{|c|}{ Force, $\mathrm{kN}$} \\
\hline$F_{\max }$ & 0.11 & 0.24 & 0.57 & 0.65 & 0.18 & 0.22 & 0.5 & 0.69 & 0.13 & 0.19 & 0.56 & 0.55 & 0.21 & 0.31 & 0.49 & 0.45 \\
\hline$F_{2}$ & 0.02 & 0.23 & 0.51 & 0.58 & 0.11 & 0.13 & 0.46 & 0.67 & 0.05 & 0.14 & 0.52 & 0.54 & 0.16 & 0.3 & 0.34 & 0.19 \\
\hline \multicolumn{17}{|c|}{ Displacement, $\mathrm{mm}$} \\
\hline$\delta_{\max }$ & 0.037 & 1.97 & 2.1 & 1.27 & 1.67 & 2.15 & 4.54 & 4.17 & 2.31 & 1.56 & 0.78 & 4.54 & 5.68 & 6.63 & 6.22 & 8 \\
\hline$\delta_{2}$ & 3.5 & 3.5 & 3.5 & 3.5 & 4 & 4.4 & 6.58 & 4.4 & 4.5 & 4.4 & 6.58 & 4.64 & 10.54 & 7.64 & 6.98 & 9.36 \\
\hline
\end{tabular}

can be analysed. The results are summarised in Table 2. The comparison of the energies is restricted to the displacement of $3.5 \mathrm{~mm}$ as it is the recommended value for crack width in case of ULS design (RILEM TC 162-TDF: 2003).

a)

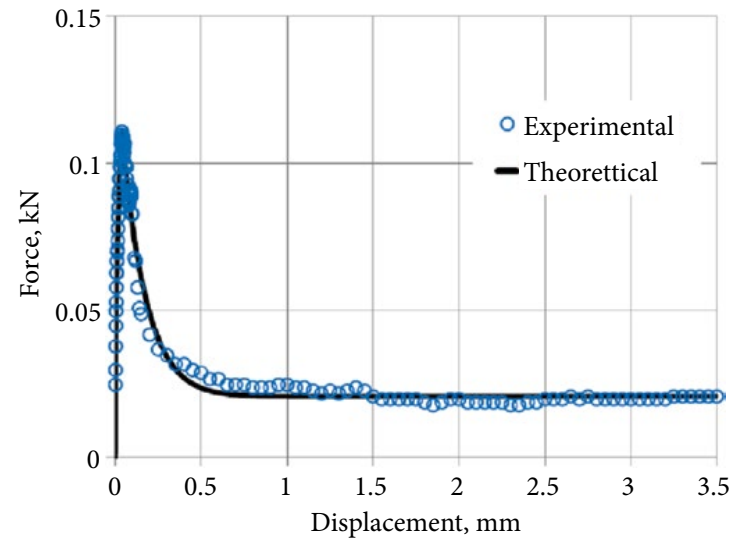

c)

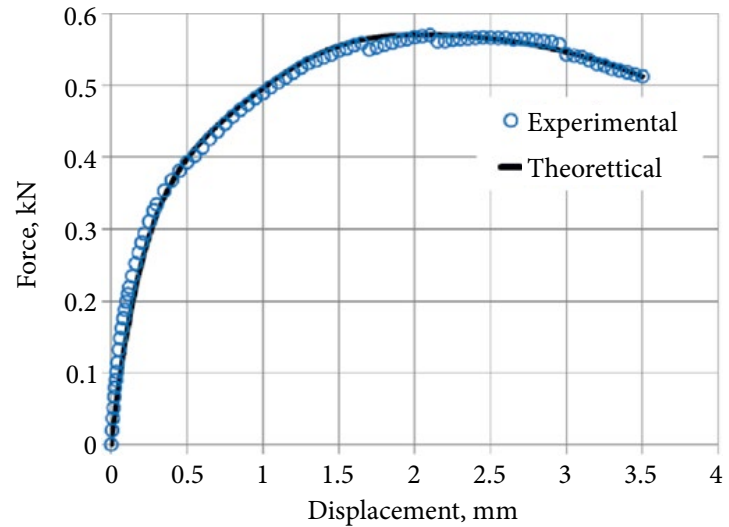

\subsection{Type effect and orientation angle}

As it is represented in Fig. 4 it is possible to increase maximum pullout force and thus the pullout energy significantly by modifying fibre geometry. Note that

b)

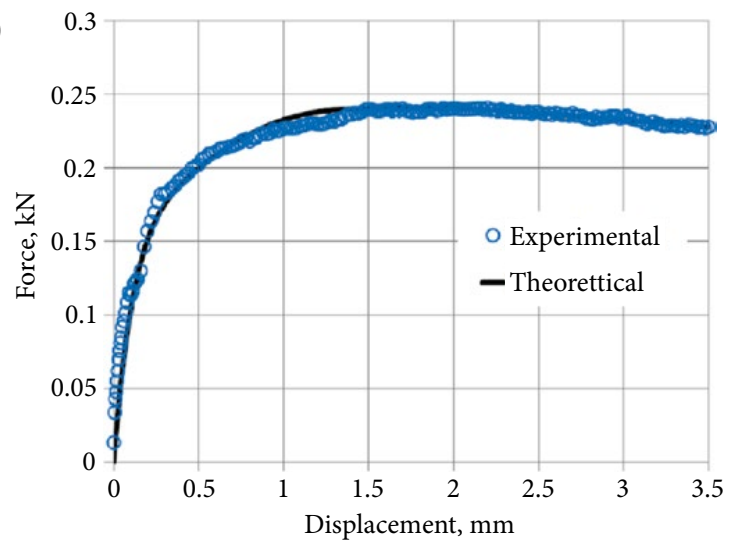

d)

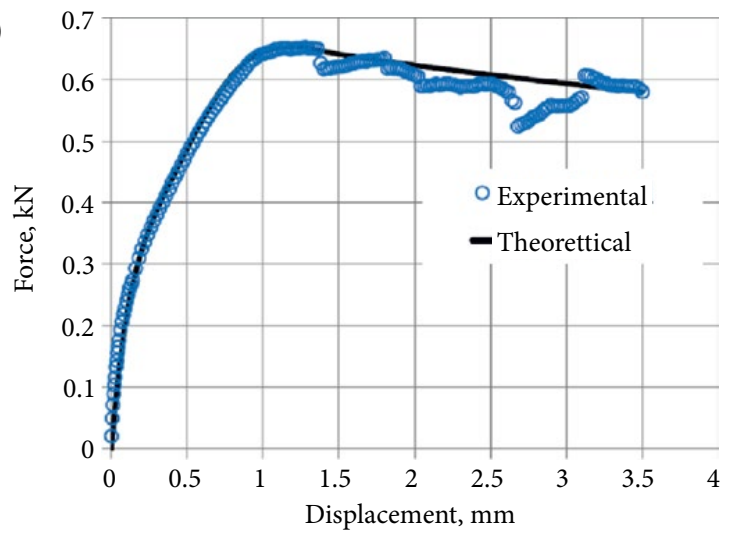

Fig. 4. Pullout response of different types of fibre: a) smooth (S), b) hooked (H), c) crimped (C), d) flat-ended (FE) 
this effect is for aligned fibres where the angle between fibre and the applied load is zero. The amount of aligned fibres in FRC composites is relatively small. Therefore the fibre type effect needs to be studied together with the effect of fibre orientation. Thus additional complexities are introduced to the pullout behaviour due to bending of the fibre and matrix spalling (Ouyang et al. 1994).

Fibre type effect on pullout energy for different inclination angles and displacements is summarised in Table 2.

Fig. 5 shows the effect of type taking smooth fibres (S) as a reference point. All types of fibres are involved in stress transferring process equally for very small slip $(0.1 \mathrm{~mm})$. Nevertheless, the effect is notable at the displacement of $3.5 \mathrm{~mm}$. The energy necessary

Table 2. Fibre type effect on pullout energy

\begin{tabular}{|c|c|c|c|c|}
\hline \multirow{2}{*}{$\begin{array}{l}\text { Displacement, } \\
\mathrm{mm}\end{array}$} & \multicolumn{4}{|c|}{$\begin{array}{c}\text { Pullout energy } W(\mathrm{~J}) \text { for different types } \\
\text { of fibres }\end{array}$} \\
\hline & S & $\mathrm{H}$ & $\mathrm{C}$ & $\mathrm{FE}$ \\
\hline \multicolumn{5}{|c|}{0 degrees } \\
\hline 0.1 & 0.009 & 0.006 & 0.008 & 0.012 \\
\hline 0.5 & 0.024 & 0.073 & 0.131 & 0.164 \\
\hline 1.0 & 0.035 & 0.183 & 0.357 & 0.457 \\
\hline 2.0 & 0.056 & 0.422 & 0.905 & 1.098 \\
\hline 3.5 & 0.087 & 0.774 & 1.732 & 1.999 \\
\hline \multicolumn{5}{|c|}{30 degrees } \\
\hline 0.1 & 0.002 & 0.001 & 0.000 & 0.001 \\
\hline 0.5 & 0.032 & 0.028 & 0.006 & 0.031 \\
\hline 1.0 & 0.098 & 0.089 & 0.039 & 0.122 \\
\hline 2.0 & 0.270 & 0.275 & 0.240 & 0.479 \\
\hline 3.5 & 0.502 & 0.582 & 0.845 & 1.370 \\
\hline \multicolumn{5}{|c|}{45 degrees } \\
\hline 0.1 & 0.002 & 0.001 & 0.000 & 0.001 \\
\hline 0.5 & 0.033 & 0.024 & 0.011 & 0.021 \\
\hline 1.0 & 0.084 & 0.080 & 0.044 & 0.079 \\
\hline 2.0 & 0.203 & 0.256 & 0.183 & 0.301 \\
\hline 3.5 & 0.394 & 0.505 & 0.604 & 0.887 \\
\hline \multicolumn{5}{|c|}{60 degrees } \\
\hline 0.1 & 0.001 & 0.000 & 0.000 & 0.000 \\
\hline 0.5 & 0.016 & 0.004 & 0.008 & 0.006 \\
\hline 1.0 & 0.045 & 0.014 & 0.026 & 0.022 \\
\hline 2.0 & 0.106 & 0.054 & 0.078 & 0.090 \\
\hline 3.5 & 0.250 & 0.193 & 0.207 & 0.279 \\
\hline
\end{tabular}

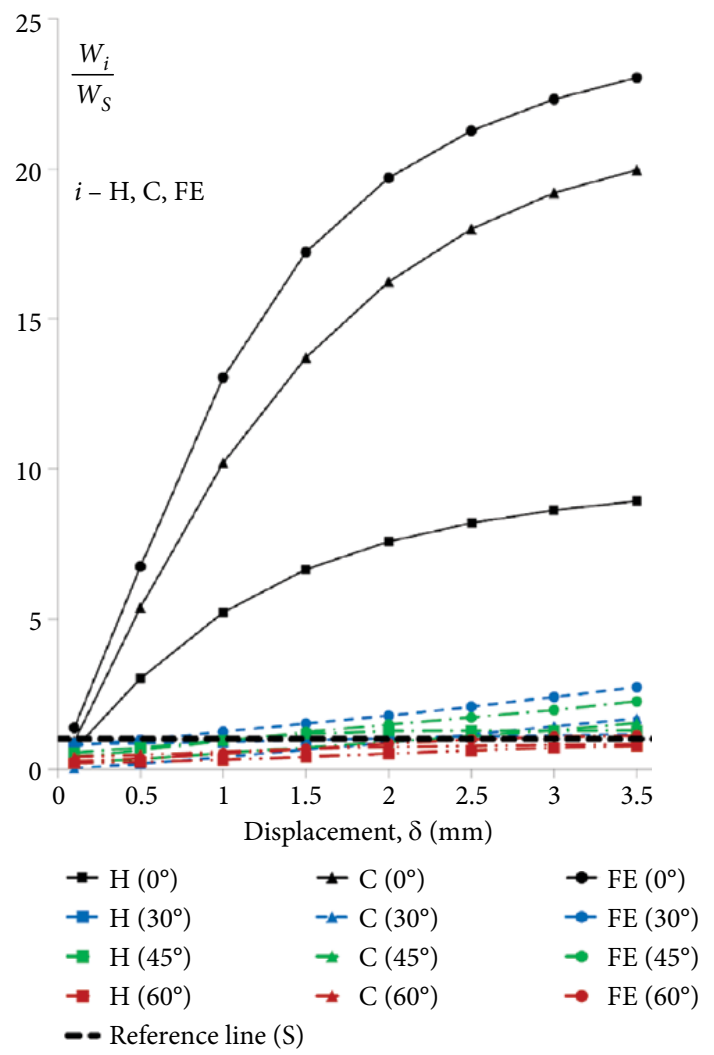

Fig. 5. Fibre type effect on pullout energy depending on fibre orientation angle: $\mathrm{S}$ - smooth, $\mathrm{H}$ - hooked, $\mathrm{C}$ - crimped, FE - flat-ended fibres

to pull out hooked $(\mathrm{H})$ fibres comparing with smooth ones is almost 9 times more. Crimped (C) and flatended (FE) fibres show even greater effect, respectively, 20 and 23 times bigger energy consumption than for smooth ones.

However, the energy is very much influenced by the fibre orientation angle. The difference between smooth and pre-deformed fibres is much smaller for bigger inclination angles. Moreover, the energy consumed to pull out a fibre from concrete till $3.5 \mathrm{~mm}$ is almost the same for all types of fibres, if they are inclined at the angle of 60 degrees.

The significant reduction of the type effect is governed by two phenomena. On one hand, the pullout energy for pre-deformed fibres decreases with increasing inclination angle at small displacements. Due to the concrete spalling process the pre-peak branch is rather gently sloping and, although the maximum force is almost the same or even in some cases higher, it is reached much later than it is for fibres aligned with the applied force (Ouyang et al. 1994). It is well represented in Table 1. For example, the displacement $\delta_{\max }$ at the maximum force $F_{\max }$ varies from 5 to $8 \mathrm{~mm}$ for 
fibres with inclination angle of 60 degrees, which is far beyond the mentioned $3.5 \mathrm{~mm}$.

On the other hand, the pullout energy for smooth fibres, which are used as the reference point, increases with increasing inclination angle due to the friction at the exit point (Laranjeira et al. 2010).

Although the total pullout energy of fibres with embedment length of, for example, $25 \mathrm{~mm}$, is greater for deformed fibres (hooked, crimped, flat-ended) than for smooth ones, the effect is intangible for relatively small slippage displacement.

\subsection{Embedment length}

Another significant parameter, especially in the case of smooth and crimped fibres, is the length of embedment. As the distribution of fibres in SFRC composite is random, the embedment length at a crack can vary from zero to the half of fibre length.

In general, for each type of fibre analysed the configuration of load-displacement curves was similar regardless the fibre embedded length. The peak load $F_{\text {max }}$, the displacement at peak load $\delta_{\text {max }}$ and the dissipated pullout energy increased with $l_{e m b}$.

Nevertheless, a slight difference can be observed. In the case of crimped fibres the maximum force is almost proportional to the embedment length. It can be explained as this type of fibre is deformed equally along the whole length.

Different behaviour was observed for flat-ended fibres. The maximum pullout force for embedment length of $15 \mathrm{~mm}$ is close to the one of $25 \mathrm{~mm}$. Note that the values represented in Fig. 6 are mean values. In fact, the absolute maximum pullout force for flatended fibres is not influenced by embedment length. In both cases, with embedment length $25 \mathrm{~mm}$ and $15 \mathrm{~mm}$ fibres mostly failed because the fibre yield strength was reached. Nevertheless, for small embedment lengths, the yield strength cannot be reached due to the concrete failure. Assuming that the ultimate force governed by the concrete failure is determined as follows

$$
F_{c, f a i l}=v_{\min } \pi\left(4 l_{e m b}+d_{h}\right)^{2} / 4,
$$

it is possible to find the fibre anchorage length where stresses in the fibre will reach their maximum value. In (8) shear stresses $v_{\text {min }}$ can be calculated according to European building code (Eurocode 2 2004); $d_{h}$ is diameter of the fibre head.

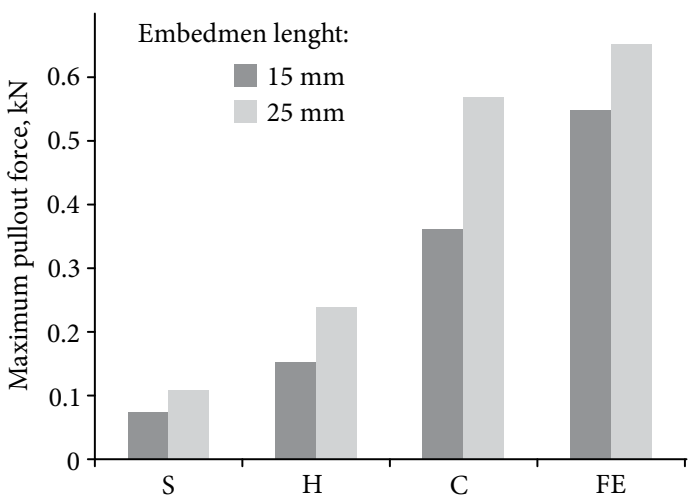

Fig. 6. Maximum pullout force depending on fibre type and embedment length

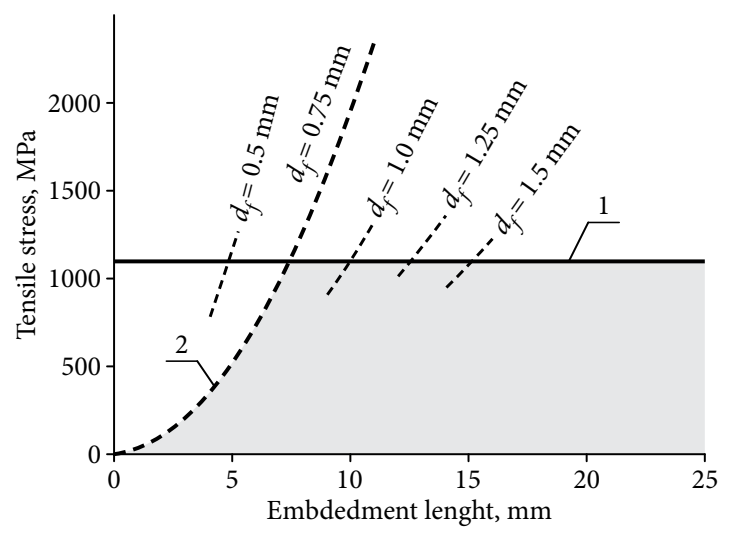

Fig. 7. Ultimate tensile stress in flat-ended fibre depending on embedment length: 1 - yield stress of fibre steel (1100 MPa),

2 - boundary governed by the tensile strength of concrete $(\mathrm{C} 50 / 60), d_{f}-$ fibre diameter

Fig. 7 shows the theoretical ultimate stress in a flat-ended fibre depending on embedment length. Flatended fibres with small embedment length have a little or no effect on post crack behaviour in FRC elements or they are not used effectively.

Analyzing crack formation phenomena, a minimum length of the embedment can also be set for other types of fibres. The crack surface in concrete is not plane. It is because the crack follows the path of least resistance. An idealised crack plane can cross a fibre, but the real crack will most likely form around its head (see Fig. 8). Crack tends to change direction and run parallel to the inclined fibre for a significant distance along its length, rather than crossing it (Bentur et al. 1985). Thus the fibres with small anchorages can have a little positive effect for the ultimate tensile strength, but they will give no contribution in the bridging mechanism after the crack formation. The distance $a$ (in Fig. 8), which stands for horizontal projection of minimum embedment length, can differ depending on fibre type, concrete strength and the orientation of the fibre. 


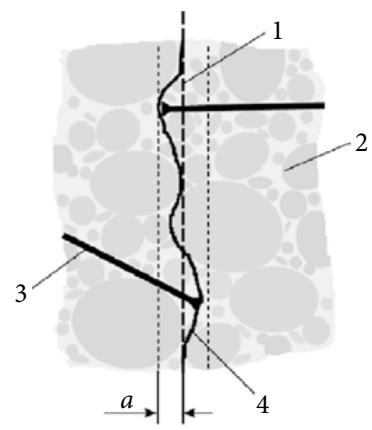

Fig. 8. Crack formation in SFRC: 1 - idealised crack plane, 2 - concrete, 3 - fibres, 4 - micro crack, $a$ is horizontal projection of minimum embedment length

\section{Bridging models}

The bridging process could be examined at small piece of FRC with a single arbitrary orientated steel fibre (Fig. 9). There is a micro crack in the matrix due to applied tensile stresses. The anchorage of the fibre is sufficient on both sides of the crack. The fibre has negligible reaction until the bond-slip in the fibre-matrix interface has yet to be developed $(w=0)$.

When crack width, $w$, increases, fibre becomes active and deformation of the fibre occurs. The pulley approach (Aveston, Kelly 1973) can be used to describe the bridging phenomena in a cracked material with the assumption that the matrix at the exit point of the fibre is rigid. The model is shown in Fig. 10. In this case the bond-slip of the fibre $\delta$ on the side of the shorter embedment is equal to the crack opening displacement $(\delta=\mathrm{w})$.

As the matrix (concrete) has a negligible tensile strength, the fibre is able to damage a part of the matrix at the exit point of the fibre. In this case, the bridging phenomena of a fibre crossing a cracked surface could be described by using the pulley that is attached to the matrix via a spring (Fig. 11).

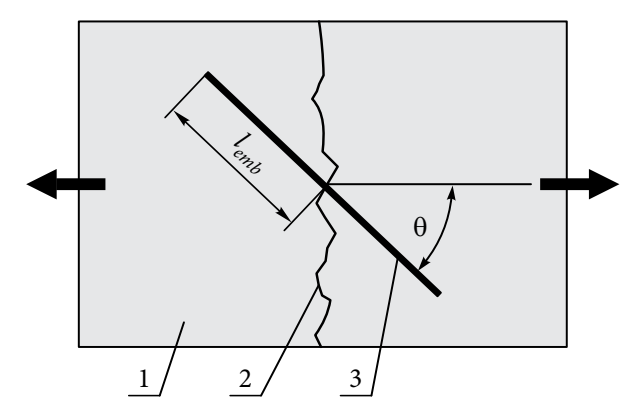

Fig. 9. Fibre at the beginning of crack formation: 1 - concrete (matrix), 2 - micro crack, 3 - fibre

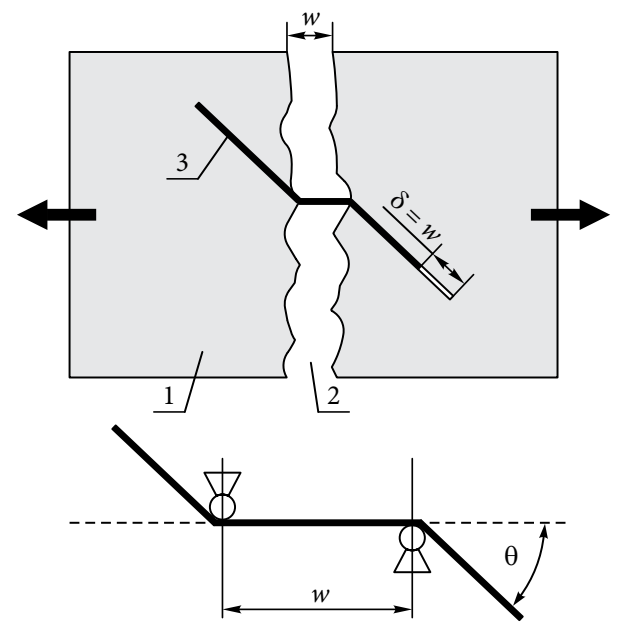

Fig. 10. Bridging model based on pulley approach by Aveston and Kelly: 1 - concrete (matrix), 2 - crack, 3 - fibre

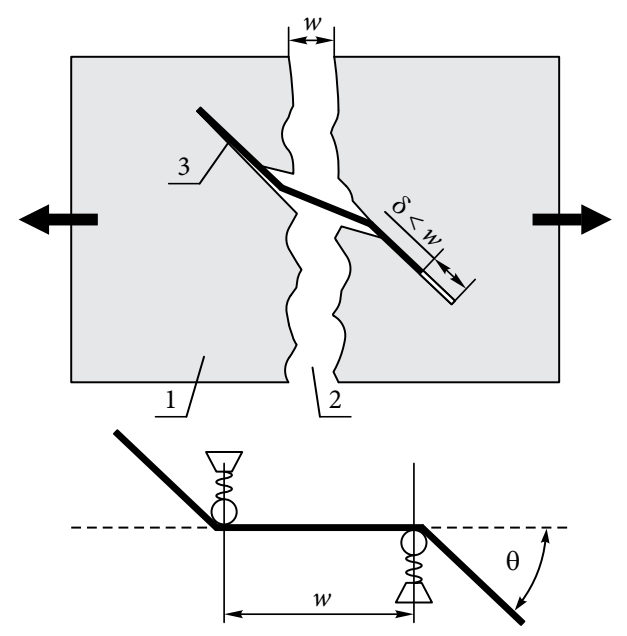

Fig. 11. Modified bridging model - pulley attached to matrix via springs: 1 - concrete (matrix), 2 - crack, 3 - fibre

In the modified model the crack opening is greater than fibre slip. The displacement for which the fibre becomes effectively involved in the tension carrying mechanism is effective width $w_{\text {eff }}$ which depends on material parameters obtained from fibre pullout tests for varying fibre orientation angle $\theta$ and fibre type (Brauns, Skadins 2010; Fantilli et al. 2008).

\subsection{Basic assumptions}

The proposed model is based on the following basic assumptions:

1) The force $F_{f}$ in a single fibre is equal to zero when crack width $w$ is smaller than the effective value $w_{\text {eff }}$ and bigger than the embedment length $l_{e m b}$. Otherwise it can be found by the following equation:

$$
F_{f}=\pi d_{f} \tau_{b}\left(l_{e m b}-w\right) .
$$


2) The effective width $w_{\text {eff }}$ is determined at half of the maximum pullout force $F_{f \text {,max }}$, i.e.

$$
w_{\text {eff }}=w \text { at } F_{f, \max } / 2 .
$$

The effective crack width at a certain orientation angle can be found by the equation in the following way:

$$
w_{\text {eff }}(\theta)=K_{1}+K_{2} \tan \theta,
$$

where $K_{1}, K_{2}$ are material parameters obtained from pullout tests.

Fibre bond strength $\tau_{b}$ is determined based on pullout tests for fibres width inclination angle $\theta=0^{\circ}$ according to expression:

$$
\tau_{b}=\frac{F_{f, \max }}{\pi d_{f} l_{e m b, e}},
$$

where $l_{e m b, e}$ - fibre embedment length in pullout test.

\subsection{Stress bridging in SFRC}

After the formation of cracks the fibres provide resistance to external structural tensile stresses in SFRC elements. Due to random distribution orientation angles and embedment lengths of the fibres are different. The tensile stresses transferred by fibres from one side of a

a)

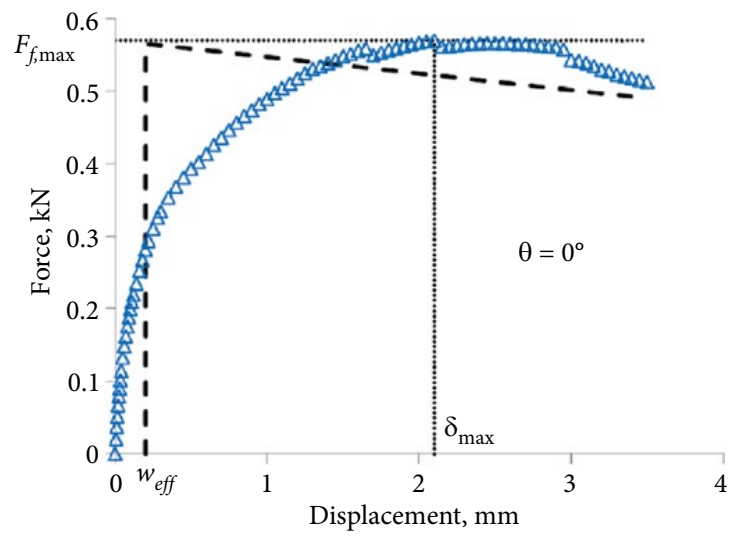

c)

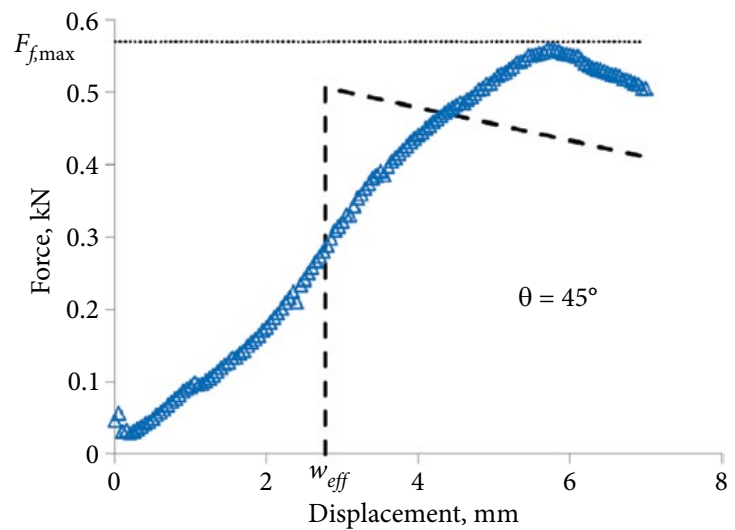

crack to the other can be determined by the following expression:

$$
\sigma_{f, \text { red }}=n_{f} V_{f, e f f} F_{f},
$$

where $n_{f}$ is the number of fibres per unit area and $V_{f, e f f}$ is the ratio of effective fibres to total number of fibres in a section.

The average force in fibres depends on fibre type, embedment length, fibre failure mechanism, orientation angle, adjacent fibres etc. In the proposed model it is assumed that the maximum force in fibres is determined for embedment length $l_{e m b, e}=l_{f} / 2$, and that the maximum force for smaller anchorages is decreasing linearly. On the bases of equations (9) and (12), the average force in a fibre $F_{f}$ can be expressed as follows:

$$
F_{f}(w)=F_{f, \max } \frac{l_{e m b}-w}{l_{f} / 2} .
$$

The pullout force values, determined by expression, (14) are compared with experimental data (Fig. 12) for various fibre angles $\theta$. Results are determined for $50 \mathrm{~mm}$ long crimped fibres and concrete strength $55.1 \mathrm{MPa}$. The bond shear stress is calculated from the test results with $\theta=0^{\circ}$ giving $\tau_{b}=9.67 \mathrm{MPa}$.

b)

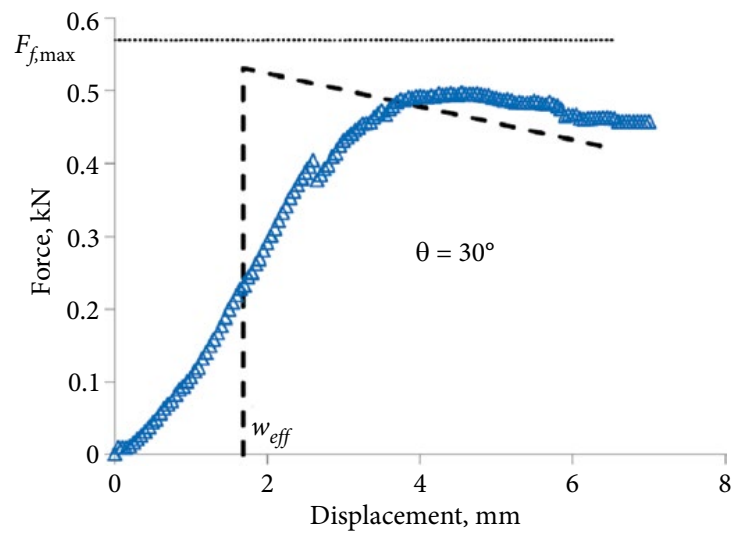

d)

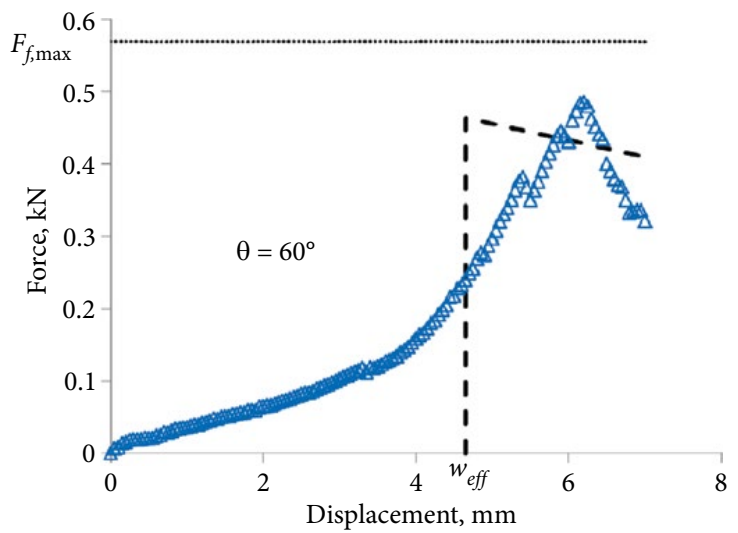

Fig. 12. Comparison of theoretical and experimental pullout force in crimped fibre 
The embedment length $l_{e m b}$ is the mean anchorage length of the fibres involved in bridging. In the crack widening process, the fibres, which are anchored less than the crack width w, are excluded from the stress bridging. Therefore, the amount of the effective fibres reduces, but the average embedment length increases. On the basis of Fig. 13 the following expression can be written:

$$
l_{e m b, i}=\frac{w_{i}+l_{f} / 2}{2},
$$

where $w_{i}$ is between 0 and $l_{f} / 2$.

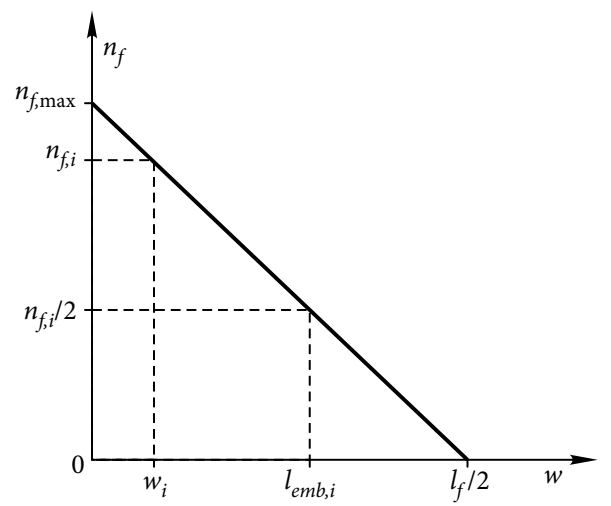

Fig. 13. Fibre amount $n_{f}$ and embedment length $l_{\text {emb }}$ depending on crack width $w$

The number of fibres $n_{f}$ crossing an idealised crack plane can be found according to equation proposed by Krenchel (1975):

$$
n_{f}=\alpha \frac{V_{f}}{A_{f}},
$$

where $V_{f}$ is the fibre volume fraction, $A_{f}$ is the cross section area of a fibre, and $\alpha$ is the fibre orientation coefficient. When the side effect is not considered the orientation factor equals to 0.5 , which represents isotropic bulk material (Dupont, Vandewalle 2005; Martinie, Roussel 2011).

Fibre amount, found by equation (16) represents the maximum value. As mentioned before, the number of fibres transferring tensile stresses decreases with increasing crack width. In the case of linear reduction, the fibre amount at a certain crack width can be determined as follows:

$$
n_{f, i}=n_{f}\left(1-\frac{w_{i}}{l_{f} / 2}\right) .
$$

\subsection{Effective fibre amount fraction}

Fibre amount in SFRC structure is one of the most important factors for post cracking behaviour. Ho- wever, it is important to know how many of them are effective. There are several conditions that make fibres effective:

- the fibres must be in tension zone;

- they must be anchored enough (in both sides of the crack);

- the orientation of fibres cannot be parallel or close to parallel to crack surface;

- the crack must be wide enough.

When ratio $V_{f, e f f}$ equals to 1.0 all fibres in a section are involved in stress transferring. On the other side, zero value shows that no fibre is effective, thus no tensile stress is being transferred.

As mentioned before, the fibres become active after cracking. However, it can be seen from the test results, that those fibres, which are more inclined, reach their maximal pullout force at a greater displacement (slip). According to the model, it is proposed that fibres are involved in bridging process when the crack is wide enough or the width of the crack $w=w_{\text {eff }}$.

As the fibres with orientation angle of 90 degrees have no effect in stress bridging, the tangent function is used to describe the relationship between effective crack width $w_{\text {eff }}$ and the fibre orientation angle $\theta$. Experimental results and theoretical function for each type of fibres is shown in Fig. 14.

Comparison of real pullout curves and proposed model is represented in Fig. 12. Relationships show that for fibres, orientated at a large angle, a significant slip is needed before mechanical locking occurs.

In the design of SFRC structures according to serviceability limit state (SLS), it is necessary to ensure comparatively small cracks in humid environment $(0.3 \mathrm{~mm})$. Although cracks can be wider in dry conditions and in the design of ultimate limit state, it is suggested to restrict them to $3.5 \mathrm{~mm}$ (RILEM TC 162-TDF: 2003). When the crack width is limited, a certain portion of fibres, crossing the crack, will not be involved in the bridging process. The critical angle $\theta_{\text {crit }}$ determining the boundary for the effective fibres can be found by using expression:

$$
\theta_{c r i t}=\arctan \left(\frac{w-K_{1}}{K_{2}}\right) .
$$

At a certain crack width, $w$, only those fibres which are inclined less than the critical angle $\theta_{\text {crit, }}$ can be taken in to account. Results for different types of fibres and crack widths are given in Table 3. 
a)

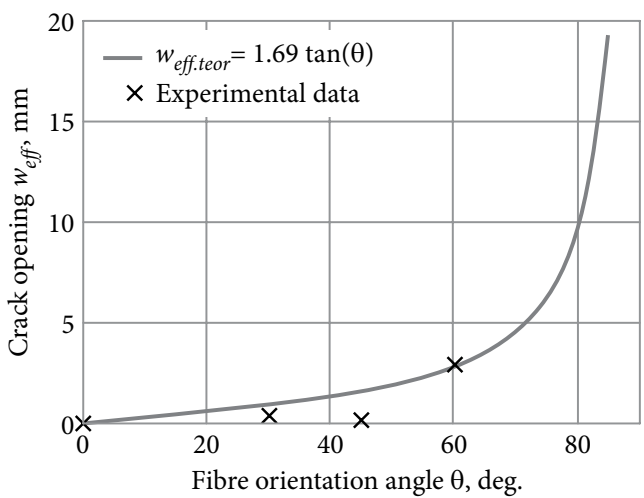

c)

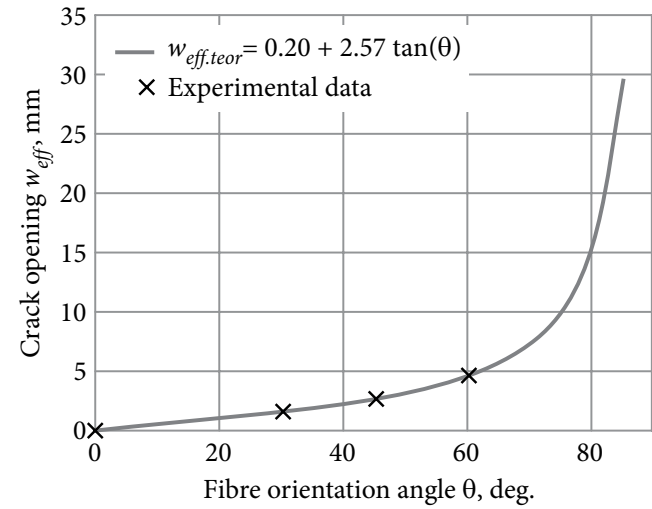

b)

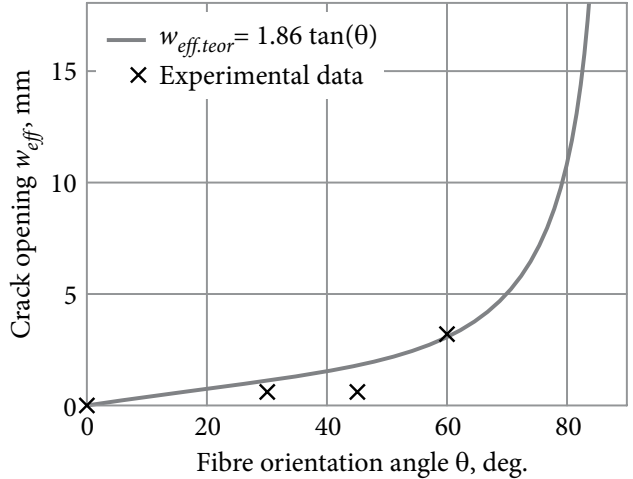

d)

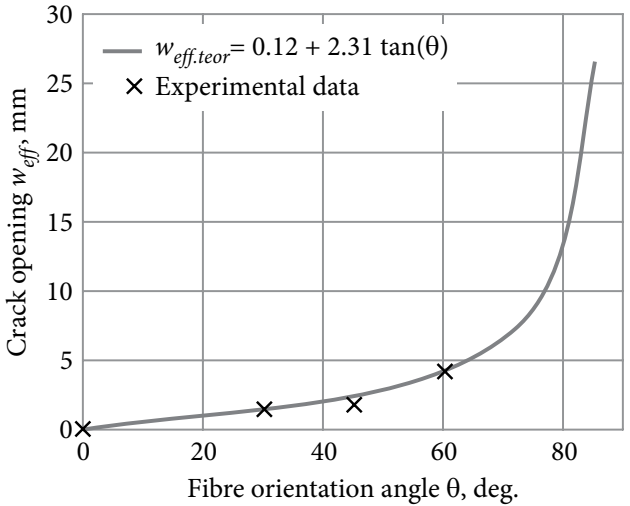

Fig. 14. Effective crack width $w_{\text {eff }}$ for different inclination angles $\theta$

Table 3. Critical angle (deg.) depending on crack width

\begin{tabular}{|c|c|c|c|c|}
\hline \multirow{2}{*}{ Fibre type } & \multicolumn{4}{|c|}{ Crack width $w(\mathrm{~mm})$} \\
\cline { 2 - 5 } & 0.5 & 1.0 & 2.0 & 3.5 \\
\hline Smooth & 17 & 31 & 50 & 64 \\
\hline Hooked-ended & 15 & 28 & 47 & 62 \\
\hline Crimped-round & 7 & 17 & 35 & 52 \\
\hline Flat-ended & 9 & 21 & 39 & 56 \\
\hline
\end{tabular}

For every fibre crossing a crack the orientation in space can be illustrated by half sphere where the centre of the sphere is the intersection point of the fibre and the crack (Fig. 15). The radius of the sphere is half of the fibre length, $l_{f} / 2$. Based on the critical angle values, half sphere can be divided into several regions, which represent the probability of a fibre to be located in the particular region. The regions show the amount of effective fibres for certain crack width. The volumes of the spherical cons represent the effective fibre amount fraction.

For example, if a SFRC structural element is designed according to SLS and must satisfy the crack width limit $w_{k}=0.5 \mathrm{~mm}$, only the fibres within the region A can be taken into account.
If no SLS requirements are considered and the element is being designed according to ultimate limit state, limiting the crack width to $3.5 \mathrm{~mm}$, fibres from the regions $\mathrm{A}$ to $\mathrm{D}$ can be taken into account.

Region E represents three groups of fibres: 1) fibres parallel or close to parallel to the crack plane; 2) fibres with embedment length smaller than the minimum anchorage length; 3 ) fibres with inclination angle greater than the critical angle $\theta_{\text {crit }}$ for $w=3.5 \mathrm{~mm}$ given in Table 3.

The effective fibre amount fraction can be determined by following expression:

$$
V_{f, \text { eff }}=1-\cos \theta_{\text {crit }}-\frac{a^{3} \tan ^{2} \theta_{\text {crit }}}{2\left(l_{f} / 2\right)^{3}},
$$

which is a relative volume of spherical cone (see Fig. 15).

The expression (19) can be written using crack width limit $w_{k}$ and parameters $K_{1}$ and $K_{2}$ from equations (11) and (18):

$V_{f, e f f}=1-\left[\left(\frac{w_{k}-K_{1}}{K_{2}}\right)^{2}+1\right]^{-0.5}-\frac{a^{3}\left(\frac{w_{k}-K_{1}}{K_{2}}\right)^{2}}{2\left(l_{f} / 2\right)^{3}}$ 


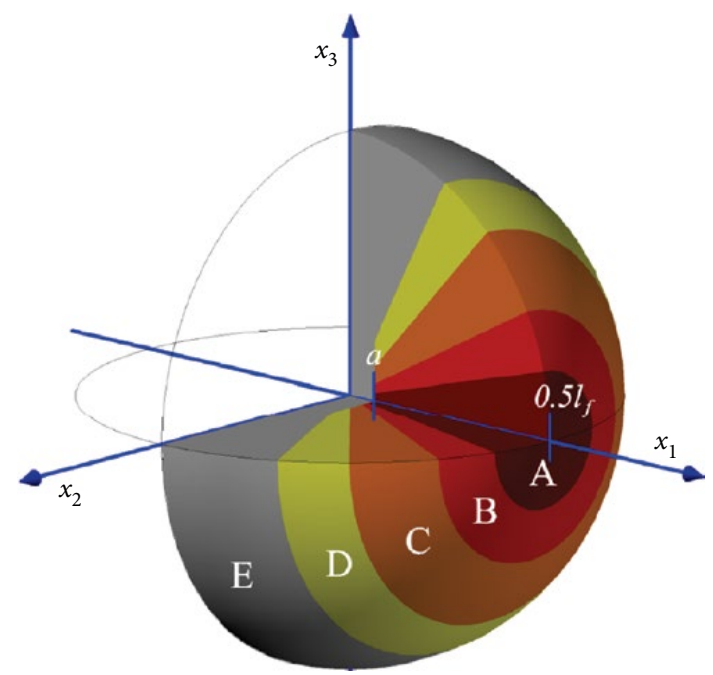

Fig. 15. Regions of effective fibres for different crack width limits: $\mathrm{A}-w_{k}=0.5 \mathrm{~mm}, \mathrm{~B}-w_{k}=1.0 \mathrm{~mm}, \mathrm{C}-w_{k}=2.0 \mathrm{~mm}$,

$\mathrm{D}-w_{k}=3.5 \mathrm{~mm}, \mathrm{E}-$ fibres excluded from bridging.

$x_{2}-x_{3}-$ crack plane, $x_{1}-$ direction of tensile stresses

The equations (19) and (20) are valid in case of uniform crack width, which can be expected for members loaded in pure tension. In the case of flexural elements the crack width is variable. At limit state the maximum crack width equals to the limit $w_{k}$, but near to the neutral axis it decreases till zero (Fig. 16). Assuming that the crack width is changing linearly, the effective fibre amount fraction can be determined by integrating equation (20):

$$
V_{f, \text { eff }}=\frac{1}{w_{k}} \int_{w_{k}}^{w_{k}} V_{f, \text { eff }}(w) d w .
$$

The number of fibres determined by the equation (17) in the case of flexure can be expressed by the following equation:

$$
n_{f, i}=n_{f}\left(1-\frac{w_{\max , i}}{l_{f}}\right),
$$

where $w_{\max , i}$ - maximum crack width.

\subsection{Numerical example}

Let us examine the stress distribution in tensile fibres of a flexural SFRC element with fibre volume fraction $V_{f}=1.0 \%$ and no side effect on fibre orientation is taken into consideration $(\alpha=0.5)$. In the calculations characteristic quantities $F_{f, \text { max }}, K_{1}$, and $K_{2}$ are used, which are determined from specimens with concrete cube strength of 55.0 MPa. Dimensions of fibres: length $l_{f}=50 \mathrm{~mm}$ diameter $d_{f}=0.75 \mathrm{~mm}$. Results for different types of fibres are shown in Fig. 17.
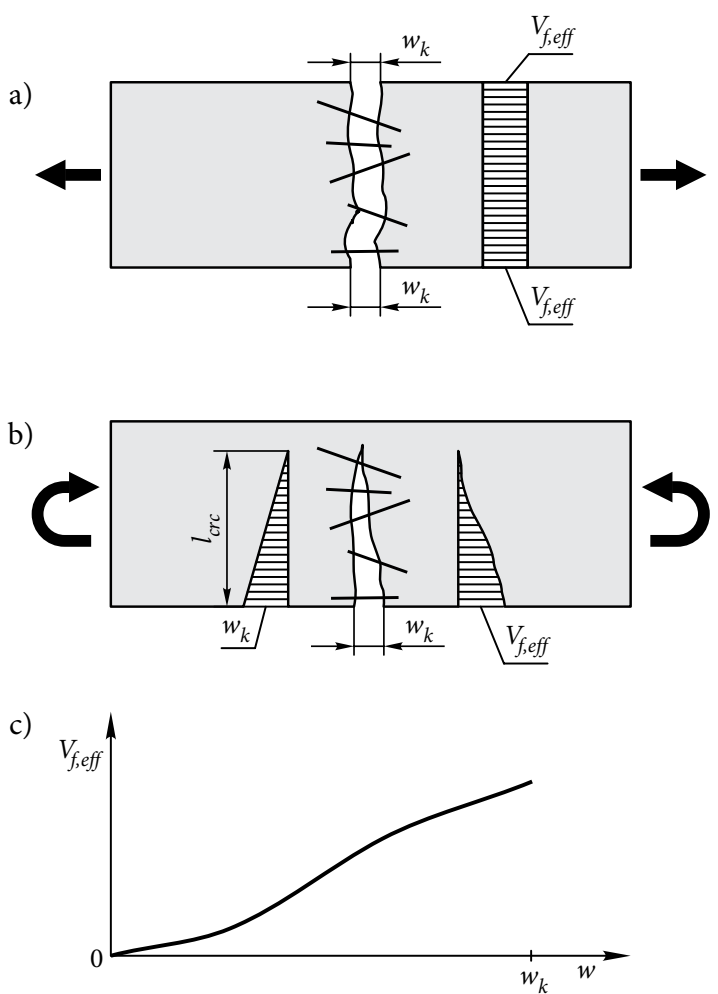

Fig. 16. Effective fibre amount fraction depending on crack width: a) in tension, b) in bending, c) effective fibre fraction

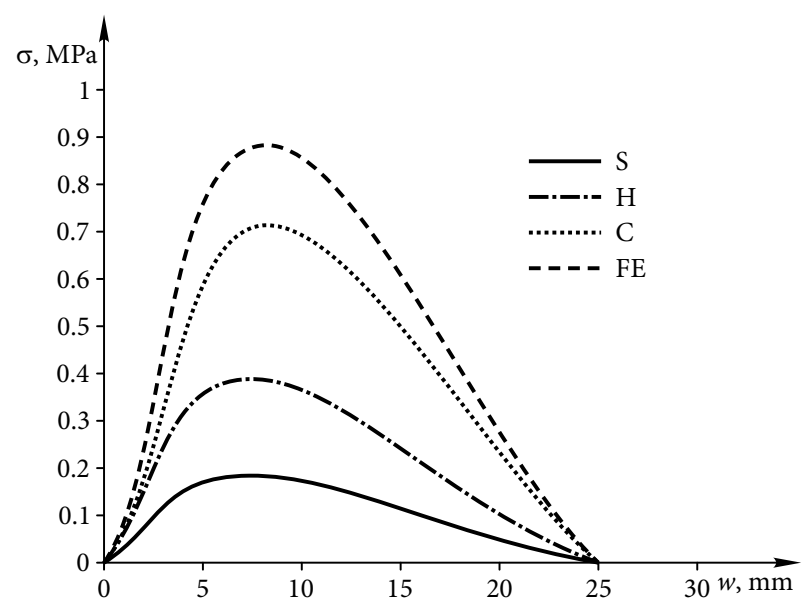

Fig. 17. Tensile stresses transferred by fibres depending on crack width

\section{Conclusions}

1. Fibre type has a significant influence on pullout energy for fibres aligned with applied force. The efficiency of fibre type for fibres inclined 30 degrees and more is inessential at relatively small displacements.

2. At a large orientation angle significant slip is needed before mechanical locking occurs.

3. For crack width limited to $3.5 \mathrm{~mm}$ (according to RILEM recommendation) only fibres with orienta- 
tion angle less than 60 degrees are effective in stress bridging, i.e., approximately $50 \%$ of all fibres crossing the crack plane.

4. The use of bi-linear approximation for average pullout experimental curves, taking into account the effective crack width, gives possibility to analyse the tensile stresses transferred by fibres crossing a crack.

\section{Acknowledgment}

The research was financially supported by ESF, contract No. 2009/0180/1DP/1.1.2.1.2/09/IPIA/VIAA/017.

\section{References}

Aveston, J.; Kelly, A. 1973. Theory of multiple fracture of fibrous composite, Journal of Materials Science 8(3): 352-362. http://dx.doi.org/10.1007/BF00550155

Bentur, A.; Diamond, S.; Mindess, S. 1985. Cracking processes in steel fiber reinforced cement paste, Cement and Concrete Research 15(2): 331-342. http://dx.doi.org/10.1016/0008-8846(85)90045-6

Brauns, J.; Skadins, U. 2010. Bond strength investigation and modelling in steel fiber concrete, in Abstracts of Intern. Conf. Mechanics of Composite Materials. Riga, 53-54.

Dupont, D.; Vandewalle, L. 2005. Distribution of steel fibres in rectangular sections, Cement and Concrete Composites 27(3): 391-398.

http://dx.doi.org/10.1016/j.cemconcomp.2004.03.005
Eurocode 2: Design of Concrete Structures. Part 1-1: General Rules and Rules for Buildings. Brussels, 2004. 225 p.

Fantilli, A. P.; Mihashi, H.; Vallini, P. 2008. Effect of bond-slip on the crack bridging capacity of steel fibers in cementbased composites, Journal of Materials in Civil Engineering 20(9): 588-598.

http://dx.doi.org/10.1061/(ASCE)0899-1561(2008)20:9(588)

Krenchel, H. 1975. Fibre spacing and specific fibre surface, in Neville, A. Fibre Reinforced Cement and Concrete. The Construction, Press, 69-79.

Laranjeira, F.; Aguado, A.; Molins, C. 2010. Predicting the pullout response of inclined straight steel fibers, Materials and Structures 43(6): 875-895.

http://dx.doi.org/10.1617/s11527-009-9553-4

Martinie, L.; Roussel, N. 2011. Simple tools for fiber orientation prediction in industrial practice, Cement and Concrete Research 41(10): 993-1000. http://dx.doi.org/10.1016/j.cemconres.2011.05.008

Ouyang, C.; Pacios, A.; Shah, P. S. 1994. Pullout of inclined fibers from cementitious matrix, Journal of Engineering Mechanics 120(12): 2641-2659.

http://dx.doi.org/10.1061/(ASCE)0733-9399(1994)120:12(2641)

RILEM TC 162-TDF: 2003. $\sigma-\varepsilon$ design method, Materials and Structures 36(262): 560-567.

Robins, P.; Austin, S.; Jones, P. 2002. Pullout behaviour of hooked steel fibres, Materials and Structures 35(7): 434-442. http://dx.doi.org/10.1007/BF02483148

Ulvis SKADINS. Doctoral student, Msc, Eng. Department of Structural Engineering, Latvia University of Agriculture. Author of 1 manual and 4 papers on international conferences. Currently he works as a lecturer in the Department of Structural Engineering at the same University. Research interests: structural problems of building engineering, strength and deformability of reinforced concrete and fiber composite materials.

Janis BRAUNS. Professor, Dr Habil Sc Eng. Department of Structural Engineering, Latvia University of Agriculture. Author of 7 monographs and 77 scientific articles. Research interests: structural problems of building engineering, stability of shells and plates, strength and deformability of composite materials and composite structures, environmental effects on structures. 